\title{
Ratings Changes, Ratings Levels, and the Predictive Value of Analysts' Recommendations
}

\author{
Brad M. Barber, Reuven Lehavy, and Brett Trueman*
}

\begin{abstract}
We show that abnormal returns to analysts' recommendations stem from both the ratings levels assigned and the changes in those ratings. Conditional on the ratings change, buy and strong buy recommendations have greater returns than do holds, sells, and strong sells. Conditional on the ratings level, upgrades earn the highest returns and downgrades the lowest. We also find that both ratings levels and changes predict future unexpected earnings and the associated market reaction. Our results imply that 1) investment returns may be enhanced by conditioning on both recommendation levels and changes; 2) the predictive power of analysts' recommendations reflects, at least partially, analysts' ability to generate valuable private information; and 3) some inconsistency exists between analysts' ratings and the formal ratings definitions issued by securities firms.
\end{abstract}

It has been well established in the academic literature that analysts' stock recommendations can predict security returns. ${ }^{1}$ What has not been established is whether this predictive power stems from the ratings level assigned by analysts or the change in the ratings level (or both). The goal of this paper is to provide insights into the sources of recommendations' predictive value and, as a consequence, enhance our understanding of how they can best be employed as part of an investment strategy.

Virtually all of the research papers to date that analyze recommendation returns focus on either ratings changes or ratings levels, but not both. Since changes and levels are positively correlated, such analyses cannot generate insights into the source(s) of recommendations' predictive value. In contrast, we include both recommendation levels and changes in our analysis. This allows us to calculate the stock returns associated with changes in analysts' ratings, conditional on ratings level, and the returns associated with analyst ratings levels, conditional on ratings change. We find that both ratings changes and ratings levels have incremental predictive power for security returns.

In a recent paper, Jegadeesh et al. (2004) examine both ratings changes and levels. They find that the magnitude of analyst consensus recommendation changes is significantly associated with future returns. In contrast, no significant relation is found between the consensus recommendation levels, themselves, and future returns (after controlling for other known drivers of stock returns).

This paper has benefited from the comments of the editor (Bill Christie), an anonymous referee, and seminar participants at Barclays Global Investors and Rice University.

\footnotetext{
* Brad M. Barber is a Professor of Finance at University of California, Davis in Davis, California, USA. Reuven Lehavy is a Professor of Accounting at the University of Michigan in Ann Arbor, Michigan, USA. Brett Trueman is a Professor of Accounting at UCLA in Los Angeles, California, USA.
}

${ }^{1}$ See, for example, Stickel (1995), Womack (1996), Barber et al. (2001), Jegadeesh and Kim (2006), and Green (2006). 
The methodology employed by Jegadeesh et al. (2004), however, makes it unlikely that they are fully capturing the value of analyst recommendations. They form consensus recommendation level and change portfolios only once a quarter. They then measure portfolio returns over the subsequent six months, with the composition of each portfolio remaining fixed during that period. As Barber et al. (2001) show, portfolio returns are diminished by delaying for a few weeks the rebalancing of portfolios following consensus recommendation changes, as well as by not rebalancing portfolios daily. ${ }^{2}$ It is unclear how Jegadeesh et al.'s methodology impacts their conclusions.

Our analysis avoids these potential issues. Our return accumulation period begins when an analyst initiates coverage, reiterates his or her recommendation, or changes it, and ends when a subsequent recommendation is issued or coverage is dropped. This procedure ensures that there is no delay in the accumulation of recommendation returns.

As a prelude to our main analysis, we compare returns across ratings levels, independent of whether a particular recommendation represents an upgrade, downgrade, reiteration, or initiation. We also compare returns across ratings changes, unconditional on whether the recommendation level is a buy, hold, or sell. Consistent with findings of Barber et al. (2001), average daily abnormal returns generally decrease as we move from more favorable to less favorable recommendations. They range from 1.0 and 0.7 basis points for strong buys and buys, respectively, to -2.5 and -2.4 basis points for sells and strong sells, respectively.

Returns also generally increase with the favorableness of a recommendation change. Upgrades are associated with an average daily abnormal return of 1.9 basis points versus 0.5 for initiations and reiterations, and -1.0 for downgrades. The magnitude of an upgrade, however, is not significantly related to average abnormal return. In contrast, average daily abnormal returns decrease with downgrade magnitude, ranging from -0.7 basis points for downgrades of only one ratings level to -1.6 and -4.4 basis points for downgrades of two and three ratings levels, respectively.

Jegadeesh et al. (2004) find that the relation between recommendation level and abnormal return becomes insignificant after controlling for price and earnings momentum. To determine whether the delays that are introduced into their portfolio formation process might be driving their result, we replicate the construction of their price and earnings momentum index. We then partition our sample of recommendations into quintiles according to index value. Within each momentum quintile, we again find that the average daily abnormal return for buys and strong buys is reliably greater than that for sells and strong sells (with the difference ranging between 2.0 and 3.9 basis points), indicating that recommendation levels have explanatory value for future returns, even conditional on price and earnings momentum.

We turn next to an examination of whether ratings changes have predictive value for security returns incremental to ratings levels. We do so by computing average abnormal returns to upgrades, downgrades, and initiations/reiterations, conditional on ratings level. For each ratings level, upgrades are associated with the largest average abnormal return and downgrades, the smallest, consistent with ratings changes providing incremental predictive value for security returns over ratings levels. With respect to buy ratings, for example, upgrades generate average daily abnormal returns that are 2.7 basis points greater than that of downgrades, with the difference being reliably positive. Upgrades to hold outperform downgrades to hold by a significant 1.4 basis points.

We then examine whether ratings levels have predictive value for security returns incremental to ratings changes. We do so by conditioning on the sign and magnitude of a ratings change and comparing average abnormal returns across recommendation levels. If levels do have incremental

\footnotetext{
${ }^{2}$ These results are consistent with findings reported in Stickel (1995) and Womack (1996).
} 
predictive value, we would expect stocks with more favorable ratings to have higher average abnormal returns than stocks with less favorable ratings.

Conditioning first on upgrades of one ratings level (sometimes referred to below as single upgrades), we find that stocks rated buy or strong buy generate a significant average abnormal return of 2 basis points per day, while stocks rated hold or sell generate an insignificant 0.1 basis point average daily abnormal return. The difference of 1.8 basis points is reliably positive. ${ }^{3}$ For upgrades of two ratings levels (alternatively referred to as double upgrades), we find that stocks rated buy or strong buy are associated with a significant daily average abnormal return of 2.3 basis points; the corresponding return for stocks rated hold is an insignificant 0.5 basis points. Again, the difference between these two returns is reliably positive.

Conditioning on downgrades of one ratings level (sometimes referred to as single downgrades), the stocks rated sell or strong sell generate a significantly negative average daily abnormal return of -3.4 basis points, while those rated buy are associated with an insignificant average daily abnormal return of -0.5 basis points. The difference of -2.9 basis points is quite large and reliably negative. For downgrades of two ratings levels (alternatively referred to as double downgrades), stocks rated sell or strong sell generate a significant average daily abnormal return of -2.9 basis points; for stocks rated hold, the corresponding return is -1.4 basis points. The difference is reliably negative. Overall, these results strongly suggest that ratings levels have incremental predictive value for security returns over ratings changes. ${ }^{4}$

Consistent with our return results, we find that both ratings levels and ratings changes predict the magnitude of, as well as the price reaction to, future unexpected earnings. This is not surprising, given that earnings are a principal driver of stock prices; the ability to predict security returns also should be reflected in an ability to forecast unexpected earnings. Our test consists of regressing unexpected earnings, and separately the price reaction to unexpected earnings, on ratings levels, ratings changes, and several control variables. Both levels and changes enter significantly into the two regressions.

Our results yield a number of important insights. First, they suggest the potential for investors to enhance expected returns by conditioning their investment strategies on both recommendation levels and changes, rather than on just one or the other. This potential for improved returns is illustrated in Figure 1, which plots the cumulative daily raw returns to 1) a levels-only hedge strategy of purchasing all stocks rated buy or strong buy and selling short all stocks rated sell or strong sell, 2) a changes-only hedge strategy of purchasing all upgraded stocks and shorting all downgraded ones, and 3) a levels- and changes-based hedge strategy of purchasing all stocks receiving a double upgrade to buy or strong buy and shorting all those receiving a double downgrade to sell or strong sell. A \$1 investment in either a levels-only or a changes-only strategy at the beginning of 1986 would have grown to slightly over $\$ 7$ at the end of 2006. In contrast, that same $\$ 1$ invested in a combined levels- and changes-based strategy would have grown to over $\$ 24 .^{5}$

Second, our results provide insights into the nature of two possible mechanisms by which ratings levels and changes predict future returns. One mechanism is for recommendations to

\footnotetext{
${ }^{3}$ The differences we report occasionally deviate slightly from the differences in individual returns due to rounding.

${ }^{4}$ In line with these results, Barber et al. (2001) and Boni and Womack (2006) find that the three-day return around recommendation announcement dates varies with ratings level, conditional on ratings change. (The statistical significance of these findings, however, is not reported.)

${ }^{5}$ In untabulated results, we find that this combined strategy earns more than either the levels-based or changes-based strategy in 18 of the 21 years of our sample period. Our return results abstract from transactions costs (brokerage commissions, the bid-ask spread, and the possible impact of trades on market prices).
} 


\section{Figure 1. Value of $\$ 1$ Invested in Recommendation-Based Strategies, January 1986 through December 2006}

Plotted here are the cumulative raw returns to 1) a levels-only hedge strategy of purchasing all stocks rated buy or strong buy, and selling short all stocks rated sell or strong sell; 2) a changes-only hedge strategy of purchasing all upgraded stocks and shorting all downgraded ones; and 3) a levels- and changes-based hedge strategy of purchasing all stocks receiving a double upgrade to buy or strong buy and shorting all those receiving a double downgrade to sell or strong sell.

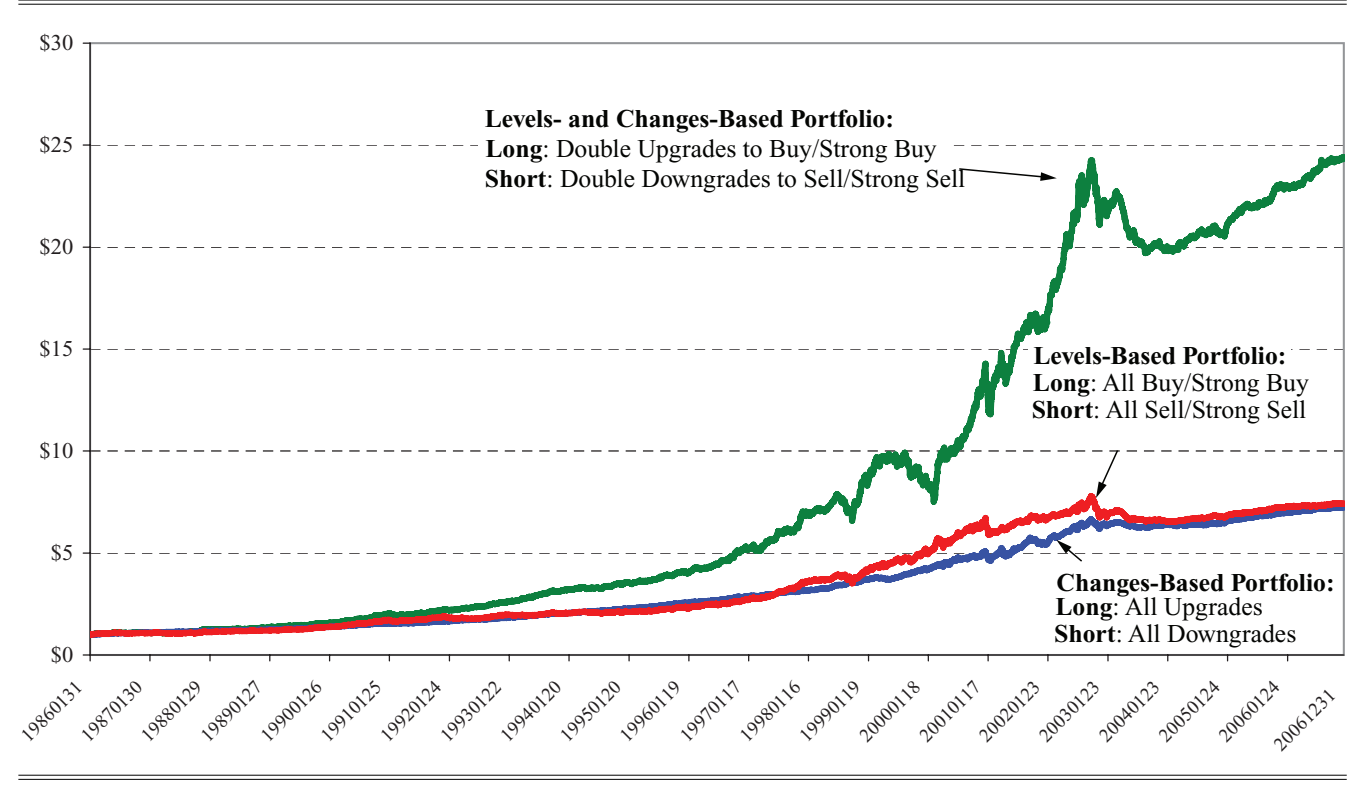

permanently shift the demand for stocks, even if the recommendations are uninformative. The other is for recommendations to convey analysts' valuable private information about the future financial success of the firms they cover (or, equivalently, their superior interpretation of relevant public information). In the latter case, recommendations should be predictive of future unexpected earnings. Moreover, to the extent that prices do not fully and instantaneously adjust to the information content of the recommendations, they should also be able to predict the price reactions to unexpected earnings. Our findings that recommendations (both levels and changes) do have the ability to forecast future unexpected earnings as well as the associated price reaction provide strong evidence that the predictive power of analysts' recommendations does not stem solely from their ability to shift investor demand. Rather, it reflects, at least in part, their ability to gather relevant private financial information. ${ }^{6}$

A third insight of our analysis relates to the consistency between analysts' recommendations and the formal ratings definitions issued by securities firms. These definitions are quite uniform across firms. At its core, a buy or strong buy means that an analyst expects the stock price to increase (sometimes by a certain minimum amount), either on an absolute or relative basis over a specified time (usually the next 12 to 18 months); a sell or strong sell means that the expected

\footnotetext{
${ }^{6} \mathrm{~A}$ similar conclusion is reached by Loh and Mian (2006).
} 
stock return is negative; and a hold means that the expected return is close to zero. ${ }^{7}$ These definitions are independent of the prior recommendation level (if any), implying that realized recommendation returns should be independent of whether a recommendation is an upgrade, downgrade, reiteration, or initiation. That this is contradicted by our results strongly suggests that analysts do not strictly abide by the formal ratings definitions when issuing recommendations. This observation contributes to the debate over whether analysts' alleged conflicts of interests (as outlined in complaints leading up to the 2003 Global Research Analyst Settlement) have led to a divergence between analysts' stock ratings and their true investment opinions. ${ }^{8}$

The plan of this paper is as follows. In Section I we describe our sample and research design. This is followed in Section II by an examination of the unconditional abnormal returns to strategies based on ratings levels and ratings changes. In Section III we investigate the extent to which these abnormal returns are robust to controls for price and earnings momentum. The incremental predictive value of ratings changes and ratings levels is examined in Sections IV and V. Section VI contains a summary and conclusions.

\section{Sample Selection, Descriptive Statistics, and Research Design}

Our initial sample consists of all recommendations on the Zacks database from January 1986 through December 1995 and all real-time recommendations on the First Call database from January 1996 through the end of $2006 .{ }^{9}$ From this sample, we drop all recommendations on Zacks with a start date prior to January 1, 1986, and all recommendations on First Call with a start date prior to January 1, 1996.

Both databases code recommendations using a five-point scale, ranging from 1 for strong buy to 5 for strong sell. While the databases employ a five-point scale, some brokers choose to issue only three different ratings - the equivalent of buy, hold, and sell—while still others switch between a five-point and a three-point scale during our sample period. ${ }^{10}$ The recommendations of the brokers who use a three-point scale are sometimes coded in these databases as 1,3 , and 5; in other cases, they are coded as 2, 3, and 4 . For uniformity we recode all such recommendations as 1,3 , and 5 .

\footnotetext{
${ }^{7}$ For example, WR Hambrecht defines a buy as a stock that is "expected in absolute dollar terms to appreciate at least $10 \%$ over the next 6 months," a hold as a stock that is "expected to appreciate or depreciate in absolute dollar terms less than $10 \%$ over the next 6 months," and a sell as a stock that is "expected to depreciate in absolute dollar terms at least $10 \%$ over the next 6 months."

${ }^{8}$ In its complaint against Salomon Smith Barney (SSB), for example, the SEC said that an e-mail written by a director who provided research management support "suggested that the common terms SSB used to rate stocks did not mean what they said: 'various people in research and media relations are very easy targets for irate phone calls from clients, reporters, etc. who make a very literal reading of the rating.... [I]f someone wants to read the rating system for exactly what it says they have a perfect right to do that."' See Boni and Womack (2002) for an extensive discussion of analysts' alleged conflicts of interests.

${ }^{9}$ Comparing the IBES recommendation databases of 2002 and 2004, Ljungqvist, Malloy, and Marston (2009) document a large number of ex post changes to the recommendation records for the 1993-2002 period. They posit that these changes influenced some of the conclusions reached by academics using the data. In light of their findings, we conducted a similar analysis on the First Call database. We find very high consistency between the historical recommendations of databases produced in different years, strongly suggesting that First Call does not suffer from the same problem that Ljungqvist, Malloy, and Marston find in IBES.

${ }^{10}$ Motivated by the implementation of NASD Rule 2711 in September 2002, many brokers switched from five-point to three-point scales. The rule requires, in part, that each analyst research report disclose the percentage of its outstanding recommendations that fall into each of three categories - buys, holds, and sells-regardless of whether the broker internally uses more than three possible ratings to characterize its recommendations. For an in-depth discussion and analysis of the switch in ratings scales, see Kadan et al. (2009).
} 


\section{Table I. Transition Matrix of Analyst Recommendations, 1986-2006}

This table shows the number of recommendations in our sample, partitioned according to prior and current recommendation levels. The number of initiations in the database (first-time recommendations as well as recommendations for firms that were previously dropped from coverage) is also presented. Below the number of recommendations for each partition is the percentage that those recommendations make up of the total. Fractional recommendations are rounded to the nearest whole value. Data for 1986-1995 come from the Zacks database; for 1996-2006, the First Call database is the source for recommendations.

\begin{tabular}{lcccccc}
\hline \hline & \multicolumn{7}{c}{ To Recommendation of } \\
\cline { 2 - 7 } & Strong Buy & Buy & Hold & Sell & Strong Sell & Total \\
\hline From recommendation of & & & & & & \\
Strong buy & 78,655 & 45,348 & 59,388 & 1,564 & 2,985 & 187,940 \\
\% of total & 7.8 & 4.5 & 5.9 & 0.2 & 0.3 & \\
Buy & 43,335 & 50,971 & 54,241 & 3,686 & 1,969 & 154,202 \\
\% of total & 4.3 & 5.1 & 5.4 & 0.4 & 0.2 & \\
Hold & 47,954 & 43,616 & 91,792 & 14,653 & 16,480 & 214,495 \\
\% of total & 4.8 & 4.4 & 9.2 & 1.5 & 1.6 & \\
Sell & 1,276 & 3,081 & 13,941 & 5,939 & 4,375 & 28,612 \\
\% of total & 0.1 & 0.3 & 1.4 & 0.6 & 0.4 & 31,592 \\
Strong sell & 2,103 & 1,569 & 15,423 & 4,080 & 8,417 & \\
\% of total & 0.2 & 0.2 & 1.5 & 0.4 & 0.8 & \\
Initiations & 127,328 & 93,516 & 131,811 & 13,653 & 19,469 & 385,777 \\
\% of total & 12.7 & 9.3 & 13.2 & 1.4 & 1.9 & \\
Total & 300,651 & 238,101 & 366,596 & 43,575 & 53,695 & $1,002,618$ \\
\hline \hline
\end{tabular}

Table I presents the number of recommendations in our sample, partitioned according to the prior recommendation (if any) issued by the brokerage firm and the current recommendation. Of the more than $1,000,000$ recommendations in our sample, only $9.8 \%$, or about 97,000 , are movements to, or initiations of, either sell or strong sell. The dearth of such recommendations has been well documented in the literature and is consistent with analysts' alleged reluctance to issue negative recommendations on the firms they follow. ${ }^{11}$ In contrast, revisions to, or initiations of, buy or strong buy total over 538,000 , or $53.8 \%$ of the total number of recommendation announcements. Upgrades and downgrades make up $17.6 \%$ and $20.4 \%$, respectively, of the sample; reiterations of recommendations comprise $23.5 \%$; and initiations account for the remaining $38.5 \%$ of the total.

Our principal analyses require the calculation of abnormal returns for portfolios of recommendations, partitioned according to ratings level and/or ratings change. To understand how these returns are calculated, take as an example a portfolio consisting of all stocks rated strong buy. Each such stock enters the portfolio at the close of trading on the day that the strong buy is issued (unless the announcement comes after the market close, in which case the stock enters the portfolio at the close of the following trading day). ${ }^{12}$ The stock remains in the portfolio through

\footnotetext{
${ }^{11}$ Barber et al. (2006) document the historical pattern in the percentages of buys, holds, and sells for the 1996-June 2003 time period.

${ }^{12}$ By establishing positions at the close of trading, we explicitly exclude the first trading day recommendation returns. We do so to reflect that many investors, especially small ones, likely learn of recommendations only with a delay. Green (2006) estimates that buying (selling) shares at the beginning of the trading day subsequent to the announcement of an upgrade (downgrade), rather than waiting until the end of the day, would increase returns by approximately 1.5 (2) percentage points.
} 
the close of trading on the day that the brokerage firm removes the strong buy rating (unless the recommendation removal is announced after trading hours, in which case the stock drops out of the portfolio at the close on the next trading day). ${ }^{13}$ If more than one brokerage firm has an outstanding strong buy recommendation for a particular stock on a given date, then that stock will appear multiple times in the portfolio on that date, once for each such recommendation. Each portfolio is rebalanced daily. ${ }^{14}$

Assuming an equal dollar investment in each recommendation, the portfolio return on date $t$ is given by

$$
\frac{\sum_{i=1}^{n_{t}} x_{i t} \cdot R_{i t}}{\sum_{i=1}^{n_{t}} x_{i t}}
$$

where $R_{i t}$ is the raw return on date $t$ for recommendation $i, n_{t}$ is the number of recommendations in the portfolio on that date, and $x_{i t}$ is the compounded daily return of recommendation $i$ from the close of trading on the day it is issued through day $t-1$. (The variable $x_{i t}$ equals one for a stock recommended as strong buy on day $t-1$.) This calculation yields a time series of approximately 5,000 daily portfolio returns.

Abnormal returns are calculated as the intercept, $\alpha_{j}$, from the four-factor model of Carhart (1997), found by estimating the following daily time-series regression for each portfolio $j$ :

$$
R_{t}^{j}-R_{f t}=\alpha_{j}+\beta_{j}\left(R_{m t}-R_{f t}\right)+s_{j} S M B_{t}+h_{j} H M L_{t}+u_{j} U M D_{t}+\varepsilon_{j t},
$$

where $R_{t}^{j}$ is the date $t$ return on portfolio $j, R_{f t}$ is the date $t$ risk-free rate, $R_{m t}$ is the date $t$ return on the value-weighted market index, $S M B_{t}$ is the date $t$ return on a value-weighted portfolio of small-cap stocks minus the date $t$ return on a value-weighted portfolio of large-cap stocks, $H M L_{t}$ is the date $t$ return on a value-weighted portfolio of high book-to-market stocks minus the date $t$ return on a value-weighted portfolio of low book-to-market stocks, and $U M D_{t}$ is the date $t$ return on a value-weighted portfolio of stocks recently up minus the date $t$ return on a value-weighted portfolio of stocks recently down. ${ }^{15}$ (Results are qualitatively similar when market-adjusted returns are used in place of four-factor model abnormal returns.) The regression yields parameter estimates of $\alpha_{j}, \beta_{j}, s_{j}, h_{j}$, and $u_{j}$. The regression error term is denoted by $\varepsilon_{j}$.

\section{Unconditional Abnormal Returns to Ratings Levels and Ratings Changes}

We begin this section by calculating abnormal returns for portfolios of recommendations partitioned solely by ratings level, independent of ratings change (if any). Consistent with results

\footnotetext{
${ }^{13}$ In the First Call database, we can distinguish between recommendations made before and after the close because date and time stamps are provided for each recommendation. We cannot do so for recommendations in the Zacks database because only date stamps are given.

${ }^{14}$ For those Zacks recommendations that remain in force past December 31, 1995 (when we switch to the use of the First Call database), we extend the return calculations through the recommendations' end-dates on Zacks, rather than arbitrarily cut them off on December 31. Further, any recommendation outstanding for more than one year is dropped at the end of the year, under the assumption that the recommendation has become stale by that time.

${ }^{15}$ See Ken French's online data library for factor data and a description of their calculation.
} 
in Barber et al. (2001), average daily abnormal returns generally decrease as we move from more favorable to less favorable recommendation levels. ${ }^{16}$ As presented in Table II, Panel A, strong buys and buys are associated with significant average daily abnormal returns of 1.0 and 0.7 basis points, respectively. The corresponding returns for sells and strong sells are a significant -2.5 and -2.4 basis points, respectively. The difference between the strong buy and strong sell recommendation returns, 3.4 basis points, is economically large and reliably positive. The average daily abnormal return for holds is not reliably different from zero.

We next calculate abnormal returns for portfolios of recommendations partitioned solely by ratings change, independent of ratings level. Table II, Panel B, presents the results. As expected, upgrades generate the largest average daily abnormal return, 1.9 basis points. Downgrades earn the lowest, -1.0 basis points. The difference between these returns, 2.9 basis points, is economically large and significantly greater than zero. Reiterations and initiations generate an insignificant 0.5 basis point average daily abnormal return.

Even though upgrades, overall, earn the highest returns, there is no significant association between the magnitude of an upgrade and abnormal returns. As reported in Table II, Panel C, while single and double upgrades are associated with average daily abnormal returns of 1.8 and 2.2 basis points, respectively, the difference is not reliably negative. Moreover, upgrades of three ratings levels earn an average abnormal return that is neither significantly different from zero nor reliably different from the average abnormal returns to single and double upgrades.

In contrast, a significant relation exists between the magnitude of a downgrade and abnormal returns (Panel D). Single downgrades generate a significant average daily abnormal return of -0.7 basis points, while double downgrades are associated with a significant average daily abnormal return of -1.6 basis points. The difference, -0.9 basis points, is reliably negative. Triple downgrades yield the most negative average daily abnormal return, -4.4 basis points. This is 2.8 basis points more negative than that of double downgrades and 3.7 basis points more negative than single downgrades. Both of these differences are economically large and significantly negative.

\section{Controlling for Price and Earnings Momentum}

Jegadeesh et al. (2004) report that the significant relation between ratings level and abnormal return disappears after controlling for price and earnings momentum. In this section we replicate the calculation of their momentum index while employing our portfolio formation methodology (which ensures no delay in the accumulation of recommendation returns) to test whether ratings levels and ratings changes continue to provide significant explanatory power for abnormal returns.

At the time a recommendation is issued, a momentum index score ranging between 0 and 4 is compiled. Four variables comprise the index. The first is the price momentum over the period from 252 to 127 trading days (approximately 12 to 6 months) prior to the recommendation date. Denoted by $P M O M_{-252,-127}^{i}$, it is equal to the market-adjusted return for recommended stock $i$ over that period

$$
\operatorname{PMOM}_{-252,-127}^{i}=\prod_{t=-252}^{-127}\left(1+r_{i t}\right)-\prod_{t=-252}^{-127}\left(1+r_{m t}\right)
$$

\footnotetext{
${ }^{16}$ See also Cliff (2007) for an analysis of abnormal returns to portfolios formed solely on the basis of recommendation levels.
} 


\section{Table II. Unconditional Average Daily Abnormal Returns to Ratings Levels and Ratings Changes}

This table reports the average daily percentage buy-and-hold abnormal returns (in basis points), and corresponding $t$-statistics, for recommendations partitioned according to ratings level (Panel A), ratings change (Panel B), magnitude of recommendation upgrade (Panel C), and magnitude of recommendation downgrade (Panel D). The difference in returns between various pairs of partitions is also presented. The average daily abnormal return is the intercept from a regression of the daily portfolio excess return on 1) the excess of the market return over the risk-free rate, 2 ) the difference between the daily returns of a value-weighted portfolio of small stocks and one of large stocks, 3) the difference between the daily returns of a value-weighted portfolio of high book-to-market stocks and one of low book-to-market stocks, and 4) the difference between the daily returns of a value-weighted portfolio of stocks recently up and one of stocks recently down.

\begin{tabular}{lcr}
\hline \hline & Panel A. Unconditional Returns to Ratings Levels & \\
\hline \hline Ratings Level & Average Daily Abnormal Return (bps) & t-Statistic \\
\hline Strong buy & $1.0^{* * *}$ & 3.87 \\
Buy & $0.7^{* * *}$ & 3.09 \\
Hold & -0.2 & -0.96 \\
Sell & $-2.5^{* * *}$ & -5.45 \\
Strong sell & $-2.4^{* * *}$ & -3.92 \\
Strong buy-strong sell & $3.4^{* * *}$ & 5.73 \\
Strong buy-hold & $1.3^{* * *}$ & 5.24 \\
Strong sell-hold & $-2.1^{* * *}$ & 3.90 \\
\hline
\end{tabular}

Panel B. Unconditional Returns to Ratings Changes

\begin{tabular}{lcr}
\hline \hline Ratings Change & Average Daily Abnormal Return (bps) & t-Statistic \\
\hline All upgrades & $1.9^{* * *}$ & 6.95 \\
All reit/init & $0.5^{*}$ & 1.90 \\
All downgrades & $-1.0^{* * *}$ & -3.49 \\
Upgrades-downgrades & $2.9^{* * *}$ & 13.15 \\
Upgrades-reit/init & $1.4^{* * *}$ & 8.37 \\
Downgrades-reit/init & $-1.5^{* * *}$ & -7.41 \\
\hline \hline
\end{tabular}

Panel C. Unconditional Returns across Upgrade Magnitudes

\begin{tabular}{lcr}
\hline \hline Magnitude of Upgrade & Average Daily Abnormal Return (bps) & t-Statistic \\
\hline All single upgrades & $1.8^{* * *}$ & 6.14 \\
All double upgrades & $2.2^{* * *}$ & 6.79 \\
All triple upgrades & 0.5 & 0.38 \\
Single-double & $-0.4^{*}$ & -1.82 \\
Double-triple & 1.7 & 1.31 \\
Single-triple & 1.3 & 0.97 \\
\hline \hline
\end{tabular}

Panel D. Unconditional Returns across Downgrade Magnitudes

\begin{tabular}{lcc}
\hline \hline Magnitude of Downgrade & Average Daily Abnormal Return (bps) & t-Statistic \\
\hline All single downgrades & $-0.7^{* *}$ & -2.30 \\
All double downgrades & $-1.6^{* * *}$ & -4.74 \\
All triple downgrades & $-4.4^{* * *}$ & -3.10 \\
Single-double & $0.9^{* * *}$ & 4.13 \\
Double-triple & $2.8^{* *}$ & 2.03 \\
Single-triple & $3.7^{* * *}$ & 2.67 \\
\hline
\end{tabular}

\footnotetext{
**** Significant at the 0.01 level.

** Significant at the 0.05 level.

*Significant at the 0.10 level.
} 
where $r_{i t}$ is the raw return for stock $i$ on day $t$ relative to the recommendation announcement date, and $r_{m t}$ is the value-weighted market return for that trading day. The second variable is the price momentum over the period from 126 to 1 trading day prior to the recommendation date. Denoted by $P M O M_{-126,-1}^{i}$, it is given by

$$
\operatorname{PMOM}_{-126,-1}^{i}=\prod_{t=-126}^{-1}\left(1+r_{i t}\right)-\prod_{t=-126}^{-1}\left(1+r_{m t}\right) .
$$

The third measure is the sum of the six most recent consensus analyst earnings forecast revisions for stock $i$ (as reported monthly in the IBES summary forecast database) prior to the recommendation announcement, each normalized by price. ${ }^{17}$ Denoted by $A F R_{-6,-1}^{i}$, it is given by $^{18}$

$$
A F R_{-6,-1}^{i}=\sum_{m=-6}^{-1} \frac{\left(A F_{i m}-A F_{i m-1}\right)}{P_{i m-1}},
$$

where $A F_{\text {im }}$ is the $m$ th most recent consensus analyst forecast of stock $i$ 's current year's earnings, and $P_{i m}$ is the price of the stock at the time that the consensus is calculated. ${ }^{19}$ The final component of the index measures earnings momentum and is defined as the unexpected earnings for the most recent fiscal quarter $q$ prior to the recommendation announcement date, normalized by the standard deviation of the earnings forecasts. Denoted by $S U E_{i q}$, it is given by

$$
S U E_{i q}=\frac{E P S_{i q}-A F_{i q}}{\operatorname{std}\left(A F_{i q}\right)}
$$

where $E P S_{i q}$ is the realized earnings per share of stock $i$ for quarter $q$ (as reported in the IBES database), $A F_{i q}$ is the most recent consensus analyst quarterly earnings forecast prior to the end of quarter $q$, and $\operatorname{std}\left(A F_{i q}\right)$ is the cross-sectional standard deviation of the analyst forecasts comprising the consensus. ${ }^{20}$

For each of the four measures, we assign a score of one (zero) if its magnitude is above (below) the median for all firms as of the recommendation date. The momentum index $(M I)$ for recommendation $i$ is the sum of these four scores and ranges between 0 and 4 .

For all recommendations with the same $M I$ score, we construct a portfolio of buy- and strongbuy-rated stocks and another of those rated sell or strong sell. Separately, we form a portfolio of stocks receiving upgrades and another of those receiving downgrades. For each of these four portfolios, we calculate average daily abnormal returns.

Return results for the buy/strong buy and sell/strong sell portfolios are reported in Table III, panel A. For each $M I$ score, the stocks rated buy or strong buy significantly outperform those

\footnotetext{
${ }^{17}$ While Ljungqvist, Malloy, and Marston (2009) find evidence of ex post changes in the IBES recommendation database, they do not find similar irregularities in the database of IBES earnings forecasts.

${ }^{18}$ For some firms, consensus analyst forecasts are not available on IBES for every month of the prior half year. For those firms, we use all of the consensus analyst forecasts available during that period.

${ }^{19}$ If the recommendation is made after the end of the year, but before the year's earnings are announced, then the earnings forecasts are for the year just ended.

${ }^{20}$ The individual analysts' forecasts that are used to calculate $\operatorname{std}\left(A F_{i q}\right)$ come from IBES. The variable $s t d\left(A F_{i q}\right)$ is set to 0.01 if either there are fewer than two analyst forecasts outstanding or the standard deviation of the analyst forecasts is equal to zero. This definition of unexpected earnings is used by Jegadeesh and Livnat (2006).
} 


\section{Table III. Average Daily Abnormal Returns to Ratings Levels and Ratings Changes, Conditional on Momentum Index Score}

This table reports the average daily percentage buy-and-hold abnormal returns (in basis points), and below them the corresponding $t$-statistics, for portfolios of recommendations having the same Momentum Index $(M I)$ score. The four portfolios are 1) that composed of all buy and strong buy recommendations, 2) that containing all sell and strong sell recommendations, 3) that composed of all upgrades, and 4) that containing all downgrades. Also presented is the difference between the average daily abnormal returns of the buy/strong buy portfolio and the sell/strong sell portfolio as well as the difference between the average daily abnormal returns of the upgrade and downgrade portfolios. To determine the $M I$ score for each recommendation, we calculate four measures: 1) the cumulative market-adjusted return for the recommended stock over the period from 252 to 127 days prior to the recommendation announcement, 2) the cumulative market-adjusted return for the recommended stock over the period from 126 days to 1 day prior to the announcement, 3 ) the sum of the six most recent monthly consensus analyst forecast revisions prior to the recommendation announcement, normalized by price, and 4) the difference between realized earnings and the consensus analyst forecast for the most recent quarter prior to the recommendation announcement, scaled by the standard deviation of the forecasts comprising the consensus. For each measure we assign a score of 1 (0) if its value is above (below) the median for all firms as of the recommendation date. The $M I$ score is the sum of these four individual scores and ranges from 0 to 4 . The average daily abnormal return is the intercept from a regression of the daily portfolio excess return on 1) the excess of the market return over the risk-free rate, 2) the difference between the daily returns of a value-weighted portfolio of small stocks and one of large stocks, 3 ) the difference between the daily returns of a value-weighted portfolio of high book-to-market stocks and one of low book-to-market stocks, and 4) the difference between the daily returns of a value-weighted portfolio of stocks recently up and one of stocks recently down.

\begin{tabular}{lccc}
\hline \hline & Panel A. Returns to Ratings Levels, Conditional on Momentum Index Score \\
\hline \hline $\begin{array}{l}\text { Momentum } \\
\text { Index Score }\end{array}$ & $\begin{array}{c}\text { Buyl } \\
\text { Strong Buy }\end{array}$ & $\begin{array}{c}\text { Sell/ } \\
\text { Strong Sell }\end{array}$ & $\begin{array}{c}\text { Buy/Strong Buy - } \\
\text { Sell/Strong Sell }\end{array}$ \\
\hline 0 (Lowest) & 0.8 & $-3.1^{* * *}$ & $3.9^{* * *}$ \\
1 & $(1.57)$ & $(-2.59)$ & $(3.42)$ \\
& $1.0^{* * *}$ & $-1.9^{* * *}$ & $2.9^{* * *}$ \\
2 & $(2.78)$ & $(-2.59)$ & $(4.24)$ \\
& $1.0^{* * *}$ & $-1.4^{*}$ & $2.4^{* * *}$ \\
3 & $(3.46)$ & $(-1.68)$ & $(2.96)$ \\
& $1.5^{* * *}$ & -0.5 & $2.0^{* * *}$ \\
4 (Highest) & $(4.66)$ & $(-0.71)$ & $(2.84)$ \\
& $1.5^{* * *}$ & -1.4 & $2.9^{* * *}$ \\
& $(3.38)$ & $(-1.46)$ & $(3.07)$ \\
\hline \hline
\end{tabular}

Panel B. Returns to Ratings Changes, Conditional on Momentum Index Score

\begin{tabular}{lccc}
\hline $\begin{array}{l}\text { Momentum } \\
\text { Index Score }\end{array}$ & Upgrades & Downgrades & $\begin{array}{c}\text { Upgrades- } \\
\text { Downgrades }\end{array}$ \\
\hline 0 (Lowest) & $1.5^{* *}$ & $-1.4^{* *}$ & $3.0^{* * *}$ \\
1 & $(2.57)$ & $(-2.23)$ & $(5.09)$ \\
& $2.1^{* * *}$ & -0.7 & $2.7^{* * *}$ \\
2 & $(4.64)$ & $(-1.49)$ & $(7.16)$ \\
& $2.2^{* * *}$ & -0.6 & $2.7^{* * *}$ \\
3 & $(5.97)$ & $(-1.54)$ & $(7.64)$ \\
& $2.3^{* * *}$ & 0.1 & $2.1^{* * *}$ \\
4 (Highest) & $(5.85)$ & $(0.28)$ & $(6.03)$ \\
& $2.5^{* * *}$ & -0.5 & $3.0^{* * *}$ \\
\hline \hline
\end{tabular}

\footnotetext{
*** Significant at the 0.01 level.

** Significant at the 0.05 level.

* Significant at the 0.10 level.
} 
rated sell or strong sell. The average daily abnormal return difference ranges from 2.0 basis points (for an $M I$ score of 3 ) to an economically very large 3.9 basis points (for an $M I$ score of 0 ). Conditioning on price and earnings momentum, ratings levels continue to have predictive value for security returns.

The upgrade and downgrade portfolio return results appear in Panel B. For each MI score, upgrades significantly outperform downgrades. The difference in average daily abnormal returns ranges from 2.1 basis points (for an $M I$ score of 3 ) to 3.0 basis points (for $M I$ scores of 0 and 4). As with ratings levels, ratings changes also provide predictive power for security returns, conditional on price and earnings momentum.

\section{The Incremental Predictive Value of Ratings Changes and Levels}

\section{A. Ratings Changes}

In this subsection we test whether ratings changes have predictive value for security returns incremental to that of ratings levels. If they do, then for a fixed ratings level, abnormal returns should vary across ratings changes, with upgrades generating the highest returns and downgrades the lowest. Note that our unconditional return results are insufficient to address this issue since the higher average return to upgrades could, in principle, be due to their predominantly being buy and strong buy recommendations, while the lower return to downgrades could be due to their predominantly being holds, sells, and strong sells.

As presented in Table IV, upgrades do indeed generate the highest returns and downgrades the lowest, conditional on recommendation level, consistent with ratings changes providing incremental predictive value for security returns. Within the subset of strong buy recommendations, upgrades are associated with an average daily abnormal return of 2.0 basis points, significantly greater than the 0.7 basis point average daily abnormal return for reiterations and initiations. For buy recommendations, upgrades earn an average daily abnormal return of 2.2 basis points, while downgrades generate abnormal returns that are insignificantly different from zero. The difference in returns is reliably positive. With respect to hold recommendations, downgrades earn a reliably negative average abnormal return of -1.0 basis points; the corresponding return for upgrades is insignificantly different from zero. The difference in returns is reliably negative. Within the subset of sell recommendations, downgrades are associated with a significant -3.6 basis point average daily abnormal return. Upgrades, in contrast, do not generate a return significantly different from zero. Despite this, upgrade and downgrade returns are not reliably different from each other. This is likely due, at least in part, to the small number of upgrades to sell in our sample. (They comprise less than $0.4 \%$ of the total.) The average abnormal return to downgrades, though, is significantly more negative than that for reiterations and initiations (at -1.6 basis points). Overall, our results provide strong evidence that ratings changes have incremental predictive value for security returns over ratings levels.

\section{B. Ratings Levels}

We next test whether ratings levels have predictive value for security returns incremental to ratings changes. We do so by holding fixed the sign and magnitude of the ratings change and examining whether abnormal returns vary with ratings level. If ratings levels do provide incremental predictive value over changes, then upgrades to buy and strong buy should outperform 


\section{Table IV. Average Daily Abnormal Return to Ratings Changes, Conditional on Ratings Level}

This table reports the average daily percentage buy-and-hold abnormal returns (in basis points), and below them the corresponding $t$-statistics, for recommendations partitioned according to ratings change, conditional on ratings level. The difference in returns between various pairs of partitions is also presented. The average daily abnormal return is the intercept from a regression of the daily portfolio excess return on 1) the excess of the market return over the risk-free rate, 2) the difference between the daily returns of a valueweighted portfolio of small stocks and one of large stocks, 3 ) the difference between the daily returns of a value-weighted portfolio of high book-to-market stocks and one of low book-to-market stocks, and 4) the difference between the daily returns of a value-weighted portfolio of stocks recently up and one of stocks recently down.

\begin{tabular}{lccccc}
\hline \hline Ratings Change & \multicolumn{5}{c}{ Ratings Level } \\
\cline { 2 - 6 } & Strong Buy & Buy & Hold & Sell & Strong Sell \\
\hline Upgrades & $2.0^{* * *}$ & $2.2^{* * *}$ & 0.5 & -1.0 & - \\
\multirow{2}{*}{ Reit/init } & $(6.73)$ & $(6.85)$ & $(1.02)$ & $(-0.26)$ & - \\
& $0.7^{* *}$ & $0.7^{* * *}$ & 0.0 & $-1.6^{* * *}$ & $-2.3^{* * *}$ \\
Downgrades & $(2.46)$ & $(2.65)$ & $(-0.09)$ & $(-2.84)$ & $(-3.35)$ \\
& - & -0.5 & $-1.0^{* * *}$ & $-3.6^{* * *}$ & $-2.7^{* * *}$ \\
Upgrades-downgrades & - & $(-1.44)$ & $(-3.04)$ & $(-6.32)$ & $(-3.31)$ \\
Upgrades-reit/init & - & $2.7^{* * *}$ & $1.4^{* * *}$ & 2.6 & - \\
& - & $(8.39)$ & $(3.54)$ & $(0.68)$ & - \\
Downgrades-reit/init & $1.3^{* * *}$ & $1.5^{* * *}$ & 0.5 & 0.6 & - \\
& $(6.10)$ & $(5.61)$ & $(1.30)$ & $(0.16)$ & - \\
& - & $-1.1^{* * *}$ & $-1.0^{* * *}$ & $-2.0^{* * *}$ & -0.4 \\
\hline \hline
\end{tabular}

*** Significant at the 0.01 level.

** Significant at the 0.05 level.

upgrades to hold and sell. Also, downgrades to buy should outperform downgrades to hold, sell, and strong sell. Note again that our unconditional return results cannot be used to address this issue as it is possible that the higher average returns to buys and strong buys are due to these recommendations predominantly being upgrades, while the lower average returns to holds, sells, and strong sells are due to these recommendations predominantly being downgrades.

Our test results are presented in Table V. Turning first to the subset of single upgrade recommendations (Panel A), the average daily abnormal return for buys and strong buys is a significant 2.0 basis points. In contrast, holds and sells generate an insignificant average daily abnormal return. The difference between the abnormal returns, 1.8 basis points, is reliably greater than zero. Within the subset of single downgrades (Panel B), hold, sell, and strong sell recommendations generate a significant average daily abnormal return of -0.9 basis points. For the single downgrades to sell and strong sell, the average daily abnormal return is -3.4 basis points. In contrast, the corresponding return for downgrades to buy is insignificantly different from zero. The difference of -2.9 basis points is quite large and significantly less than zero.

Turning next to the subset of double upgrades (Panel C), the average daily abnormal return for buys and strong buys is a significant 2.3 basis points. In contrast, holds earn an insignificant abnormal return. The difference, 1.9 basis points, is reliably greater than zero. For the subset 


\section{Table V. Average Daily Abnormal Return to Ratings Levels, Conditional on Ratings Change}

This table reports the average daily percentage buy-and-hold abnormal returns (in basis points) and the corresponding $t$-statistics for recommendations partitioned according to ratings level, conditional on a single upgrade or single downgrade (Panels A and B, respectively), and conditional on a double upgrade or double downgrade (Panels $\mathrm{C}$ and $\mathrm{D}$, respectively). The average daily abnormal return is the intercept from a regression of the daily portfolio excess return on 1) the excess of the market return over the risk-free rate, 2) the difference between the daily returns of a value-weighted portfolio of small stocks and one of large stocks, 3 ) the difference between the daily returns of a value-weighted portfolio of high book-to-market stocks and one of low book-to-market stocks, and 4) the difference between the daily returns of a value-weighted portfolio of stocks recently up and one of stocks recently down.

\begin{tabular}{lcr}
\hline \hline & Average Daily Abnormal Return (bps) & t-Statistic \\
\hline \hline Buy/strong buy & Panel A. Single Upgrades to & \\
Hold/sell & $2.0^{* * *}$ & 6.66 \\
Buy/strong buy-hold/sell & 0.1 & 0.26 \\
\hline \hline
\end{tabular}

Panel B. Single Downgrades to

\begin{tabular}{lll}
\hline \hline Hold/sell/strong sell & $-0.9^{* *}$ & -2.56 \\
Buy & -0.5 & -1.45 \\
Hold/sell/strong sell-buy & -0.4 & -1.31 \\
\hline Sell/strong sell & $-3.4^{* * *}$ & -6.53 \\
Buy & -0.5 & -1.45 \\
Sell/strong sell-buy & $-2.9^{* * *}$ & -5.72 \\
\hline \hline
\end{tabular}

Panel C. Double Upgrades to

\begin{tabular}{lll}
\hline \hline Buy/strong buy & $2.3^{* * *}$ & 6.95 \\
Hold & 0.5 & 0.70 \\
Buy/strong buy-hold & $1.9^{* * *}$ & 2.95
\end{tabular}

Panel D. Double Downgrades to

\begin{tabular}{lll}
\hline \hline Sell/strong sell & $-2.9^{* * *}$ & -4.06 \\
Hold & $-1.4^{* * *}$ & -4.15 \\
Sell/strong sell-hold & $-1.4^{* *}$ & -2.1 \\
\hline \hline
\end{tabular}

\footnotetext{
*** Significant at the 0.01 level.
}

${ }^{* *}$ Significant at the 0.05 level.

of double downgrades (Panel D), sell and strong sell recommendations are associated with a significant average daily abnormal return of -2.9 basis points. The corresponding return for hold recommendations is only -1.4 basis points. The difference of -1.4 basis points is reliably negative. Overall, these results provide strong evidence that ratings levels have incremental predictive value for security returns over ratings changes. ${ }^{21}$

\footnotetext{
${ }^{21}$ We perform similar analyses for the subsets of all upgrades and all downgrades (regardless of magnitude). Untabulated results reveal that the average daily abnormal return to upgrades to buy or strong buy is significantly greater than the corresponding return to upgrades to hold or sell. Similarly, the average daily abnormal return to downgrades to hold, sell, or strong sell is significantly less than the corresponding return to downgrades to buy.
} 


\section{Levels- and Changes-Based Trading Strategies}

The abnormal return findings presented in the prior two subsections suggest that investment strategies involving both recommendation levels and changes can outperform those based on either levels or changes alone. We document the return differences among various hedge strategies in Columns 1 and 2 of Table VI. As reported in Panel A, a combined levels- and changes-based hedge strategy of purchasing stocks receiving single upgrades to buy or strong buy and shorting those receiving single downgrades to sell or strong sell generates a significant average daily abnormal return of 5.5 basis points. ${ }^{22}$ In contrast, a changes-only based hedge strategy of purchasing all single upgrades and shorting all single downgrades earns an average daily abnormal return of 2.5 basis points. The difference between these returns (3.0 basis points, or over $7 \%$ annually) is economically large and significantly greater than zero. A levels-only based hedge strategy of purchasing all buys and strong buys and shorting all sells and strong sells generates an average daily abnormal return of 3.5 basis points. Again, this return is reliably less than that earned by the combined strategy.

The same pattern is found for double upgrades. As reported in Panel B, a combined levels- and changes-based strategy of purchasing stocks receiving double upgrades to buy or strong buy and shorting stocks receiving double downgrades to sell or strong sell yields a significant average daily abnormal return of 5.2 basis points. The corresponding return to a changes-only based hedge strategy of purchasing all double upgrades and shorting all double downgrades is 3.8 basis points. The difference between these two returns is reliably greater than zero. The combined strategy's average daily abnormal return is also reliably greater than that of the levels-only based strategy of purchasing all stocks rated either buy or strong buy and shorting all those rated sell or strong sell. These results clearly demonstrate the potential for enhancing investment returns by conditioning on both recommendation levels and changes rather than on one to the exclusion of the other. ${ }^{23}$

In Columns 3 through 6 of Table VI, we present the average abnormal returns to the long and short components of each hedge strategy. As the results reveal, the superiority of combined levels- and changes-based hedge strategies carries over in large measure to both their long and short components. ${ }^{24}$ As shown in Panel A, a strategy of purchasing all single upgrades to buy or strong buy generates significantly higher average abnormal returns than does either a strategy of purchasing all single upgrades or one of purchasing all buys and strong buys. Similarly, a

\footnotetext{
${ }^{22}$ This return deviates slightly from the difference between the returns to single upgrades to buy or strong buy ( 2.0 basis points) and single downgrades to sell or strong sell ( -3.4 basis points), as given in Table $\mathrm{V}$. This small discrepancy is due to rounding.

${ }^{23}$ We alternatively calculate monthly, rather than daily, hedge strategy abnormal returns (by compounding daily returns within each month and regressing the monthly returns on the monthly factor returns). In unreported results, we find that the monthly abnormal returns are of the same order of magnitude as the corresponding daily returns (multiplied by 20), albeit slightly smaller in size. All combined levels- and changes-based hedge strategies continue to earn average abnormal returns significantly higher than those generated by the corresponding levels-only and changes-only based hedge strategies, with one exception - the average abnormal return to a strategy of purchasing double upgrades to buy or strong buy and shorting double downgrades to sell or strong sell is not significantly different from that of a strategy of purchasing all double upgrades and shorting all double downgrades.

${ }^{24}$ In untabulated analysis, we generate descriptive statistics on the size composition of the firms in each of the long and short portfolios. Of note, the portfolio of single downgrades to sell or strong sell is tilted more toward smaller stocks, while the portfolio of double upgrades to buy or strong buy is tilted more toward larger stocks, relative to the corresponding levels-only and changes-only based portfolios. Further, the mean and median market caps of the portfolio of double downgrades to sell or strong sell are smaller than those of either the double downgrade or the sell and strong sell portfolio. All these differences, though, pale in comparison to the tilt toward larger stocks evident in the upgrade portfolios, as well as in the portfolio of buys and strong buys, relative to the downgrade portfolios and the portfolio of sells and strong sells.
} 


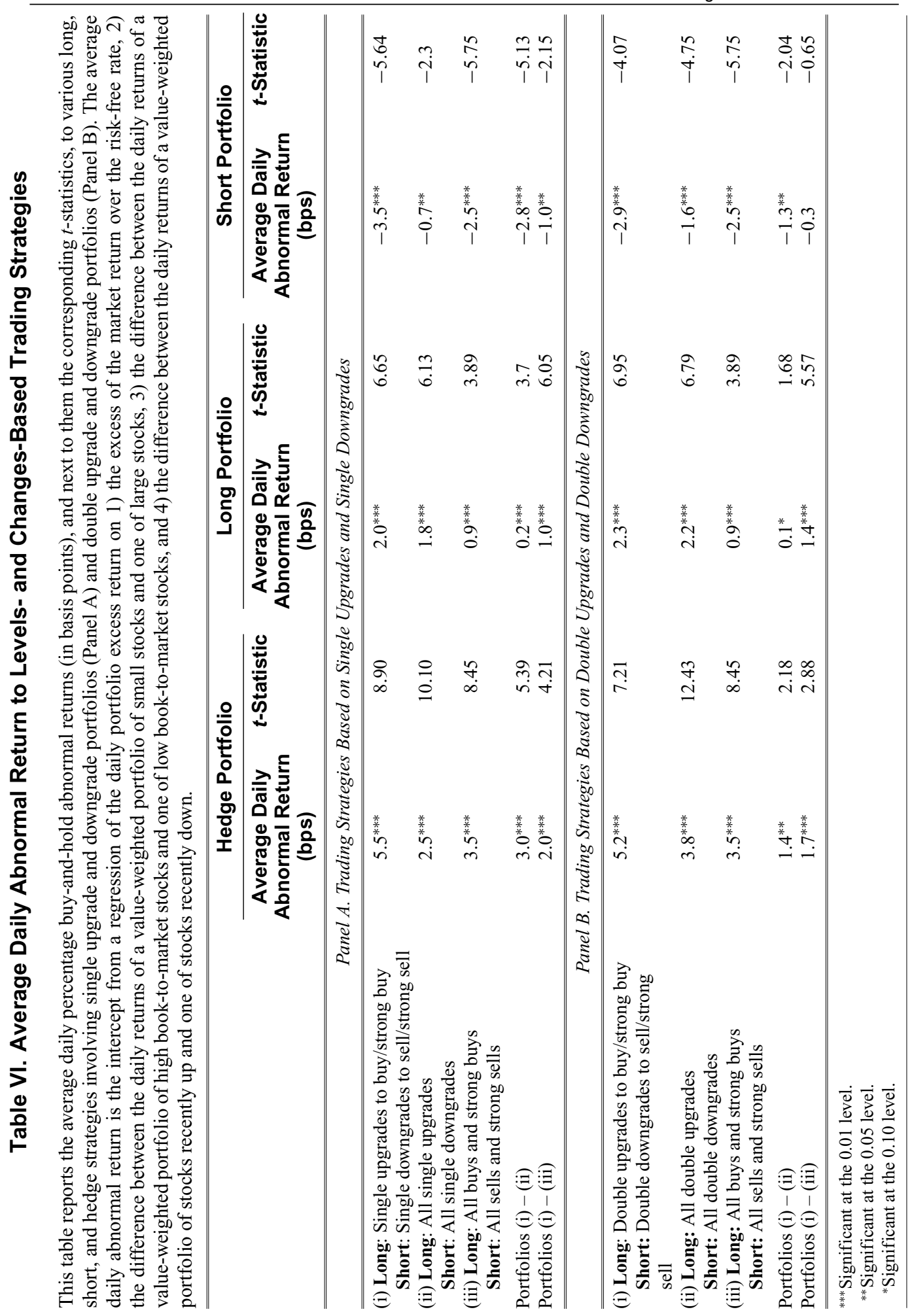


strategy of shorting all single downgrades to sell or strong sell significantly outperforms a strategy of either shorting all single downgrades or shorting all sells and strong sells. As reflected in Panel B, a portfolio of all double upgrades to buy or strong buy generates a significantly higher average abnormal return than does one of all buys and strong buys. However, it is not significantly different from the average abnormal return earned on a portfolio of all double upgrades. On the short side, a strategy of selling all double downgrades to sell or strong sell significantly outperforms a strategy of shorting all double downgrades. However, the strategy's average abnormal return is insignificantly different from that generated by shorting all sells and strong sells.

We repeat our hedge strategy analysis separately for the small, medium-sized, and large firms in our sample in order to determine whether the superiority of combined levels- and changes-based hedge strategies is in evidence across firm size categories. ${ }^{25}$ In untabulated results, we find that all of the combined strategies dominate within the small stock subsample. Combined strategies involving single-level upgrades and downgrades also dominate within the medium-sized firm subsample; those involving double level upgrades and downgrades, however, do not. There is no evidence of superior performance for combined levels- and changes-based strategies within our big firm subsample. That our findings are strongest for the small firms is not surprising and is consistent with patterns documented in numerous other studies of trading strategies.

We also calculate abnormal returns separately for each year of our sample period to ascertain whether the superiority of hedge strategies based on both levels and changes is pervasive over time or is concentrated in just a few years. Untabulated results reveal that it is not isolated to a few years. In 17 of the 21 years of our sample period, the average abnormal return to a hedge strategy of purchasing single upgrades to buy or strong buy and shorting single downgrades to sell or strong sell is greater than that of a hedge strategy of purchasing all single upgrades and shorting all single downgrades. In 18 of the years, it is greater than the average abnormal return earned by a hedge strategy of purchasing all buys and strong buys and selling all sells and strong sells. The hedge strategy of purchasing double upgrades to buy or strong buy and shorting double downgrades to sell or strong sell outperforms that of purchasing all double upgrades and shorting all double downgrades in 15 of the 21 years. Also, in 15 of the years, it outperforms the hedge strategy of purchasing all buys and strong buys and shorting all sells and short sells.

\section{Additional Evidence for the Incremental Predictive Value of Ratings Changes and Rating Levels}

As long as the incremental predictive power of ratings levels and changes for future returns is at least partly a result of analysts' possession of private information about the future financial success of the firms they cover (or, equivalently, a superior ability to interpret public financial disclosures), then it should also manifest itself in the forecasting of unexpected earnings. Moreover, to the extent that stock prices do not immediately adjust to the information content of the recommendations, levels and changes should each have incremental predictive power for the price reactions to unexpected earnings. We use these insights to design additional tests of incremental predictive value. We implement them with respect to the first quarterly earnings announcement subsequent to recommendation release.

We define unexpected earnings for firm $i$ in quarter $q$ as the difference between realized earnings, $E P S_{i q}$, and the consensus analyst earnings forecast just prior to the earnings

\footnotetext{
${ }^{25}$ Using monthly NYSE decile cutoffs, we classify firms as big if they fall within the top three deciles, small if they fall within the bottom three deciles, and medium-sized otherwise.
} 
announcement, $A F_{i q}$, scaled by the per share price of the firm, $P_{i q}$, at the end of the month preceding the announcement. Denoted by $U E_{i q}$, it is given by ${ }^{26}$

$$
U E_{i q}=\frac{E P S_{i q}-A F_{i q}}{P_{i q}} .
$$

The price reaction to the earnings announcement, $R E T_{i q}$, is defined as the market-adjusted return for stock $i$ over the three days surrounding the quarter $q$ earnings announcement. It is given by

$$
R E T_{i q}=\prod_{d=-1}^{+1}\left(1+r_{i d}\right)-\prod_{d=-1}^{+1}\left(1+r_{m d}\right)
$$

where $r_{i d}$ is the raw return for stock $i$ on day $d$, and $r_{m d}$ is the value-weighted market return on that day. Date $d=0$ is the earnings announcement day.

For each of these two measures, we run the following regression:

$$
\begin{aligned}
\text { SURP }_{i q}= & a_{0}+a_{1} \text { LEVEL }_{i q}+a_{2} \text { CHANGE }_{i q}+a_{3} U E_{i q-1} \\
& +a_{4} \text { PMOM }_{-127,-2}^{i}+a_{5} \text { AFR }_{-6,-1}^{i}+a_{6} \ln \left(M V_{i q}\right),
\end{aligned}
$$

where

$S U R P_{i q}=$ alternately $U E_{i q}$ and $R E T_{i q}$, as given by Expressions (7) and (8), respectively;

$L_{E V E L_{i q}}=$ the consensus recommendation level two days before the quarter $q$ earnings announcement for firm $i ;{ }^{27}$

$C_{H A N G E_{i q}}=$ the change in the consensus recommendation level over the period beginning 62 days before firm $i$ 's earnings announcement for quarter $q$ and ending two days prior;

$U E_{i q-1}=$ the unexpected earnings for firm $i$ in quarter $q-1$ (as defined by (7));

$P M O M_{-127,-2}^{i}=$ the market-adjusted return for firm $i$ beginning 127 days before the quarter $q$ earnings announcement and ending two days prior; ${ }^{28}$

$A F R_{-6,-1}^{i}=$ the sum of the six most recent consensus analyst forecast revisions, prior to the quarter $q$ earnings announcement, for firm $i$ 's current year earnings, each scaled by beginningof-month price, ${ }^{29}$

$\ln \left(M V_{i q}\right)=$ the natural logarithm of the market value of firm $i$ at the end of the month preceding the quarter $q$ earnings announcement.

The independent variables, $U E_{i q-1}, P M O M_{-127,-2}^{i}$, and $A F R_{-6,-1}^{i}$, serve as controls for price and earnings momentum. Their inclusion is motivated by the conclusion of Jegadeesh et al. (2004) that, controlling for price and earnings momentum, ratings levels do not have predictive value for security returns. The natural logarithm of market value, $\ln \left(M V_{i q}\right)$, is included in the regression as a control for firm size.

Table VII, Column 1 presents regression results with unexpected earnings as the dependent variable, while Column 2 reports results with the market-adjusted return serving as the dependent variable. Both regressions are based on nearly 190,000 earnings announcements. The results are

\footnotetext{
${ }^{26}$ We alternatively scale unexpected earnings by the standard deviation of analysts' forecasts. Untabulated regression results are qualitatively similar to those reported here.

${ }^{27}$ The consensus recommendation level is calculated as the average of the numerical ratings issued by all the analysts who have outstanding recommendations on the stock.

${ }^{28}$ The calculation of this variable is given by Expression (4), with Day 0 now defined as the earnings announcement date.

${ }^{29}$ The calculation of this variable is given by Expression (5).
} 
Table VII. Regression Analysis of Future Earnings Surprises and Market Reaction to Earnings Surprises on Prior Recommendation Levels and Changes

This table reports the intercept and coefficients from regressions with unexpected earnings for firm $i$ in the current quarter $q$ (Column 1) and three-day market-adjusted return around the earnings announcement (Column 2) as the dependent variable. The unexpected earnings for quarter $q$ is defined as the difference between the earnings for the quarter minus the consensus analyst forecast, scaled by share price at the end of the month prior to the announcement. The three-day market-adjusted return is equal to the share's compounded raw return, from the day before until the day after the earnings announcement, minus the corresponding compounded value-weighted market return. The current quarter $q$ is defined as the quarter whose earnings announcement is the first to follow the issuance of the recommendation. $L E V E L_{i q}$ is the consensus recommendation level for firm $i$ two days prior to quarter $q$ 's earnings announcement; $C_{C H A N E}$ iq is the change in the consensus recommendation level over the period beginning 62 days before firm $i$ 's earnings announcement for quarter $q$ and ending two days prior to the announcement; $U E_{i q-1}$ is the unexpected earnings for firm $i$ in quarter $q-1$; $P M O M^{i}{ }_{-127,-2}$ is the market-adjusted return for firm $i$ beginning 127 days before the quarter $q$ earnings announcement and ending two days prior to the announcement; $A F R_{-6,-1}^{i}$ is the sum of the revisions to the consensus analyst forecast for firm $i$ 's current year's earnings during the six months prior to the quarter $q$ earnings announcement date, scaled by beginningof-month price; and $\ln \left(M V_{i q}\right)$ is the natural logarithm of the market value of firm $i$ at the end of the month prior to the quarter $q$ earnings announcement. The $t$-statistics appear below the intercept and coefficients.

\begin{tabular}{lcc}
\hline \hline & \multicolumn{2}{c}{ Dependent Variable } \\
\cline { 2 - 3 } & $\begin{array}{c}\text { Current Quarter's } \\
\text { Unexpected Earnings }\end{array}$ & $\begin{array}{c}\text { 3-Day Market-Adjusted Return } \\
\text { around Earnings Announcement }\end{array}$ \\
\hline Intercept & $-0.0083^{* * *}$ & $0.7654^{* * *}$ \\
& $(-28.97)$ & $(4.71)$ \\
LEVEL $_{i q}$ & $-0.0007^{* * *}$ & $-0.1012^{* * *}$ \\
& $(-12.90)$ & $(-3.14)$ \\
$C H A N G E_{i q}$ & $-0.0006^{* * *}$ & $-0.3801^{* * *}$ \\
& $(-4.98)$ & $(-5.83)$ \\
$U E_{i q-1}$ & $0.1889^{* * *}$ & -0.3058 \\
$P M O M^{i}{ }_{-127,-2}$ & $(71.40)$ & $(-0.21)$ \\
& $0.0028^{* * *}$ & 0.0309 \\
$A F R^{i}{ }_{-6,-1}$ & $(32.81)$ & $(0.64)$ \\
$\ln \left(M V_{i q}\right)$ & $0.0604^{* * *}$ & $4.0523^{* * *}$ \\
$R^{2}$ & $(56.95)$ & $(6.94)$ \\
Number of observations & $0.0007^{* * *}$ & $-0.0203^{*}$ \\
\hline \hline
\end{tabular}

${ }^{* * *}$ Significant at the 0.01 level.

*Significant at the 0.10 level.

very similar across the two regressions. The coefficients on both the consensus recommendation level and the two-month change in the consensus recommendation are significantly different from zero. Both coefficients are negative, as expected, implying that the less favorable (i.e., the more positive) the consensus ratings level and the less favorable (again, the more positive) the consensus ratings change, the smaller the unexpected earnings and the smaller the associated price reaction. These results provide additional support for our conclusion that ratings levels and ratings changes both have incremental predictive power for security returns. 
Our findings also yield insights into the mechanism(s) by which ratings levels and changes predict future returns. One possible mechanism is for recommendations to increase the demand for favorably rated stocks and reduce the demand for unfavorably rated ones, independent of whether the recommendations are informative. Another possible (noncompeting) mechanism is for recommendations to convey to investors analysts' valuable private information about the future financial success of the firms they cover. Our finding that recommendations have the ability to forecast unexpected earnings and the associated price reaction provides strong evidence that the predictive power of analysts' recommendations does not stem solely from their ability to shift investor demand. Rather, it reflects, at least in part, analysts' skill at gathering relevant private financial information.

\section{Summary and Conclusions}

We provide evidence in this paper that the documented abnormal returns to analysts' recommendations are derived from both the ratings levels and the ratings changes. Conditional on ratings level, upgrades earn the highest returns and downgrades the lowest. Conditional on the sign and magnitude of a ratings change, the more favorable the recommendation level, the higher the return.

These results imply that an investment strategy based on both recommendation levels and recommendation changes has the potential to outperform one based exclusively on one or the other. Conditioning just on recommendation levels, a strategy of purchasing all stocks rated buy or strong buy and shorting all those rated sell or strong sell, for example, would have earned an average daily abnormal return of 3.5 basis points during our sample period. Conditioning just on recommendation changes, a strategy of purchasing all stocks receiving a double upgrade and shorting all those receiving a double downgrade would have generated an average daily abnormal return of 3.8 basis points. However, conditioning on both ratings changes and levels by purchasing all stocks receiving a double upgrade to buy or strong buy and shorting all those receiving a double downgrade to sell or strong sell would have yielded an average daily abnormal return of 5.2 basis points. This is a greater than 4 percentage point improvement (on an annual basis) over the levels-only based strategy and a 3.5\% annual improvement over that based solely on ratings changes.

We also find that ratings levels and changes have the ability to forecast future unexpected earnings, as well as the corresponding market reactions. In addition to providing further evidence that the abnormal returns to analysts' security recommendations are attributable to both levels and changes, this result implies that the predictive power of analysts' recommendations is not simply a product of analysts' ability to shift investor demand; rather, it reflects their skill at collecting valuable private information about the future financial success of the firms they cover.

As mentioned in the introduction, the formal ratings definitions promulgated by securities firms are fairly uniform: they call for recommendations to be based on analysts' expectation for share performance over the recommendation horizon. These expectations are independent of prior ratings level, implying that realized recommendation returns should be independent of whether a rating is an upgrade, downgrade, reiteration, or initiation. That ratings changes do have incremental predictive value for security returns suggests that analysts do not strictly follow the published ratings definitions when issuing their recommendations. This conclusion adds to the debate over whether analysts' recommendations accurately reflect their investment opinions, an issue that has been of central importance to the SEC in recent years. 


\section{References}

Barber, B., R. Lehavy, M. McNichols, and B. Trueman, 2001, "Can Investors Profit from the Prophets? Security Analyst Recommendations and Stock Returns," Journal of Finance 56, 531-563.

Barber, B., R. Lehavy, M. McNichols, and B. Trueman, 2006, "Buys, Holds, and Sells: The Distribution of Investment Banks' Stock Ratings and the Implications for the Profitability of Analysts' Recommendations," Journal of Accounting and Economics 41, 87-117.

Boni, L. and K. Womack, 2002, "Wall Street's Credibility Problem: Misaligned Incentives and Dubious Fixes," Brookings-Wharton Papers on Financial Services 1, 93-130.

Boni, L. and K. Womack, 2006, “Analysts, Industries, and Price Momentum," Journal of Financial and Quantitative Analysis 41, 85-109.

Carhart, M., 1997, “On Persistence in Mutual Fund Performance,” Journal of Finance 52, 57-82.

Cliff, M., 2007, “Do Affiliated Analysts Mean What They Say?” Financial Management 36, 1-25.

Green, T.C., 2006, "The Value of Client Access to Analyst Recommendations," Journal of Financial and Quantitative Analysis 41, 1-24.

Jegadeesh, N. and W. Kim, 2006, "Value of Analyst Recommendations: International Evidence," Journal of Financial Markets 9, 274-309.

Jegadeesh, N., J. Kim, S. Krische, and C. Lee, 2004, “Analyzing the Analysts: When Do Recommendations Add Value?," Journal of Finance 59, 1083-1124.

Jegadeesh, N. and J. Livnat, 2006, "Revenue Surprises and Stock Returns," Journal of Accounting and Economics 41, 147-171.

Kadan, O., L. Madureira, R. Wang, and T. Zach, 2009, "Conflicts of Interest and Stock Recommendations: The Effects of the Global Settlement and Related Regulations," Review of Financial Studies 22, 41894217.

Ljungqvist, A., C. Malloy, and F. Marston, 2009, “Rewriting History,” Journal of Finance 64, 1935-1960.

Loh, R. and M. Mian, 2006, "Do Accurate Earnings Forecasts Facilitate Superior Investment Recommendations?" Journal of Financial Economics 80, 455-483.

Stickel, S., 1995, "The Anatomy of the Performance of Buy and Sell Recommendations," Financial Analysts Journal 51, 25-39.

Womack, K., 1996, “Do Brokerage Analysts' Recommendations Have Investment Value?" Journal of Finance 51, 137-167. 